gegen eine gute Trennung von Dehydrocpiandrosteron, Androsteron und Ätiocholanolon. Der Vorteil der Durchlaufchromatographic liegt darin, daß man die Laufzeit nach Belieben verlängern und die Trennung damit verbessern kann. Nach 60-70 Min. ist die schnellste Substanz (Androsteron) in der Nähe der Front. Die 11-oxygenierten 17-Ketosteroide haben eine viel geringere Laufgeschwindigkeit als Ätiocholanolon. Sie sind somit auf dieser Platte in diesem System nicht getrennt. $\mathrm{Zu}$ ihrer Trennung verwenden wir Aluminiumoxid G-Platten mit höherer Aktivität, die wir nach dem Durchlaufverfahren im System Äthylacetat/Cyclohexan $(65: 35)$ entwickeln. Nach einer Laufzeit von 3 Stdn. sind die 11-oxygenierten Verbindungen gut getrennt, während Androsteron, Dehydroepiandrosteron und Ätiocholanolon bereits bis zur Front durchgelaufen sind. Die für die Durchlaufchromatographie verwendeten Kammern lassen sich ohne große Kosten aus den üblichen Chromatographiegefäßen herstellen. Wir haben mit dieser Anordnung immer gute Trennungen erzielt.

Wenn der Harnextrakt stark gefärbt ist, was häufig bei pathologisch veränderten Harnen vorkommt, wird zu viel Verunreinigung mit auf die Dünnschichtplatte aufgetragen. Vom Startfleck zieht sich dann ein brauner „Schwanz" bis in die Mittc der Platte und stört besonders die Bestimmung der 11-oxygenierten Steroide. Man erhält dann $z u$ hohe Werte. Durch eine einfache Filtration durch eine kleine Aluminiumoxidsäule läßt sich der Extrakt gut und leicht vorreinigen.
Dabei werden $97-99 \%$ der vorgelegten Steroide wiedergefunden.

Die Kombination von enzymatischer Hydrolyse und Solvolyse führt zu einer praktisch vollständigen Spaltung der Konjugate (7). In mehreren zuvor enzymatisch und solvolytisch hydrolysierten Harnen, die mit Äthylacetat extrahiert waren, fanden sich nach anschließender "saurer Hydrolyse" und Extraktion mit Äther nur noch etwa $1 \%$ der ursprünglich durch enzymatische Hydrolyse gefundenen Gesamt-17-Ketosteroide.

Bei allen untersuchten Harnen bestimmten wir gleichzeitig die Gesamt-17-Ketosteroide nach der Methode von ZimmermanN in der Modifikation von WaLter (9). Bei 30 Harnen betrug die Summe der sieben chromatographisch getrennten Steroide durchschnittlich $84 \%$ der sog. Gesamt-17-Ketosteroide. Die Bestimmung der Gesamt-17-Ketosteroide nach ZIMMERMANN ist bekanntlich nicht ganz spezifisch und gibt stets zu hohe Werte. Die Summe der dünnschichtchromatographisch getrennten Steroide dürfte also dem ,wahren" 17-Ketosteroidgehalt etwa entsprechen. Die Methode trennt die wichtigsten 17-Ketosteroide, nämlich Dehydroepiandrosteron, Androsteron, Ätiocholanolon, $11 \beta$-Hydroxyandrosteron, 11-Ketoandrosteron, $11 \beta$-Hydroxyätiocholanolon und 11-Ketoätiocholanolon schnell, sauber und spezifisch. Sowohl Empfindlichkeit als auch Richtigkeit und Genauigkeit sind gut. Deshalb ist die Methode für die routinemäßige Bestimmung dieser Verbindungen geeignet.

\title{
Literatur
}

1. Reisert, P. M. und D. Schumacher, Experientia 19, 84 (1963). - 2. Chang Shen, N. H., F. E. Francis und R. A. Kinsella, J. Laborat. Clin. Med., S. Louis 60, 1017 (1962). - 3. StiRKA, L., J. Sulcovi, J. Riedlovi und O. Adamec, Clin. chim. Acta (Amsterdam) 9, 168 (1964). - 4. Hamman, B. L. und M. M. Martin, J. Clin. Endocr., Springfield 24, 1195 (1964). - 5. Suliarovici, S., B. Lunenfeld und M. C. Shelesnyak, Acta endocr.,
K'hvn. 51, 447 (1966). - 6. Starnes, W. R., A. H. Rhodes und R. H. Lindsay, J. Clin. Endocr., Springfield 26, 1245 (1966). 7. Baulieu, E. E. und M. F. Jayle, Analyse des Steroides Hormonaux, Tome I, S. 73, Masson et Cie., Paris (1961). - 8. Drekter, I. J., G. R. Scism, S. Stern, S. Pearson und T. H. McGavaCK, J. Clin. Endocr., Springfield 12, 55 (1952). - 9. WaLter, K., Klin. Wschr. 30, 474 (1952).

\section{Erfahrungen über die optimale Darstellung und Diagnostik der Gc-Typen ${ }^{1}$ )}

\author{
Von R. HII.GÉRMANN \\ Aus dem Institut für gerichtliche Medizin der Universität Marburg (Direktor: Prof. Dr. F. Scbleyer)
}

(Eingegangen am 20. Mai 1967)

\begin{abstract}
Die Zuverlässigkeit der Variante der immunoelektrophoretischen Mikromethode auf Glasplatten zur Gc-Klassifizierung wurde geprüft. Die Vorteile dieses Verfahrens und seine besondere Eignung in der Routinediagnostik werden gegenüber der Objektträgermethode hervorgehoben. Es wird gezeigt, daß sich nicht nur auf Grund zahlreicher verfahrensmäßiger Modifikationen, sondern auch bei scheinbar gleichen Versuchsbedingungen unterschiedliche Auftrennungszeiten ergeben. Daher wird empfohlen, die Laufstrecke der Proteine als Richtgröße festzulegen, um reproduzierbare Ergebnisse zu erhalten. Der Calciumlactatpuffer erlaubt eine zuverlässigere Diagnostik als der Michaelispuffer.

The rcliability of the modified immuno-electrophoretic micromethod on glass plates was tested. The advantages of this procedure over the slide method, and its special suitability for routine diagnosis are shown. Variations in the separation times, which are not entircly duc to the many modifications of the method, are observed, even under apparently identical test conditions. It is therefore recommended that the proteins are always allowed to migrate the same distance in order to obtain reproducible results. Calcium lactate buffer is morc reliable than Michaelis buffer for diagnosis.
\end{abstract}

1) Auszugsweise vorgetragen auf der 45. Tagung der Gesellschaft für gerichtliche Medizin, Freiburg 1966. 
Die Literatur enthält zahlreiche Vorschläge zur Modifizierung der Gc-Bestimmungsmethodik unter Ausschaltung möglicher Fehlerquellen. Nach zahlreichen Vorversuchen haben wir uns für die von Bartscr und Mitarbeiter (1) angegebene Mikromethode auf einer großen Glasplatte mit 40 Einzelbestimmungen entschieden, weil sie alle Arbeitsgänge gegenüber der Objektträgermethode erleichtert und vereinfacht. Weitere Mikromethoden auf Glasplatten haben SCHLESINGER, Vogt und Prokop (15) sowie Bundschum, Marek und GESERICK (2) beschrieben.

\section{Methodik}

\section{Puffersystem}

Wir verwenden den von Hirschfeld $(8,9)$ modifizierten, leicht alkalischen ( $\mathrm{pH} \mathrm{8,6)} \mathrm{Barbital-Calciumlactatpuffer} \mathrm{nach} \mathrm{LAURELL}$ u. a. (10). Es empfiehlt sich, für den Agarpuffer geringere Mengen der Substanzen einzuwviegen, da für die Agarberstellung jeweils nur wenige $\mathrm{m} l$ Puffer benötigt werden und die Haltbarkeit des Puffers begrenzt ist.

\section{Elektrodenpuffer}

$\begin{array}{lr}\text { Veronal } & 6,9 \mathrm{~g} \\ \text { Veronal-Natrium } & 43,8 \mathrm{~g} \\ \text { Calciumlactat } & 1,92 \mathrm{~g} \\ \text { Aqua dest. ad } & 5000,00 \mathrm{~m} l\end{array}$

\begin{tabular}{lr}
\multicolumn{3}{c}{ Agarpuffer } \\
Veronal & $1,66 \mathrm{~g}$ \\
Veronal-Natrium & $10,51 \mathrm{~g}$ \\
Calciumlactat & $1,536 \mathrm{~g}$ \\
Aqua dest. ad & $1000,00 \mathrm{ml}$
\end{tabular}

Die Substanzen lassen sich in heißem Aqua dest. leichter lösen; sie sollen jedoch nicht lange gekocht werden, da Calciumlactat hitzelabil ist [STöss, u. a. (16)]. Der Elektrodenpuffer sollte nur einmal verwendet werden. $\mathrm{Zu}$ Vergleichsuntersuchungen wurde außerdem der Veronal-Natriumpuffer nach MrCHAELIs ( $\mathrm{pH} 8,6, \mu=0,1$ ) geprüft.

\section{Herstellung des Agargels}

Dic Agarzubereitung richtet sich im wesentlichen nach den von Hirschfeld $(8,9)$ angegebenen Vorschriften. Wir verwenden den Difco Spezial-Agar-Noble (Hersteller: Difco Laboratories, Detroit), bei dem sich unseres Erachtens eine zusätzliche Reinigung durch weitere Waschvorgänge erübrigt. Neben dem Reinagar wird auch Agarose der Behringwerke empfohlen, die nach Untersuchungen von ENGEL (4) eine bessere Transparenz, schärfere Präzipitationslinien und günstigere lineare Trennung der Fraktionen gewährleistet. $2 \mathrm{~g}$ Agar werden in $100 \mathrm{~m} l$ Aqua dest. im Wasserbad (Erlenmeyer-Kolben) gelöst. Nach Hinzufügen eines auf etwa $80^{\circ}$ erwärmten Gemisches aus $66 \mathrm{ml}$ Agarpuffer und $34 \mathrm{ml}$ Aqua dest. wird weiterhin so lange im Wasserbad erhitzt, bis eine gut durchmischte, klare Lösung entsteht.

Als Gelträger dienen $115 \times 300 \mathrm{~mm}$ messende, $6 \mathrm{~mm}$ starke Glasplatten aus völlig ebenem Spiegelglas, deren Kanten abgeschrägt sind. Auf je 2 sorgfältig fettfrei gereinigte und mittels Wasserwaage justierte Glasplatten wird das unter einer Wasserstrahlpumpe luftblasenfrei gemachte, heißflüssige $1 \%$ Agarsol bis zu einer Schichtdicke von etwa $2 \mathrm{~mm}$ aufgegossen. Wenn man ein bei der Plattenmethode nicht störendes, sondern eher erwünschtes Abschwimmen des Gels von der Unterlage während des Wässerns vermeiden will, läßt sich eine bessere Haftung des Gels dadurch erzielen, daß man die Glasplatten vor dem Aufgießen des Agarsols mit einem dünnen, gut angetrockneten Agarfilm imprägniert.

Nach Erstarren des Gels werden mit einer großen Stanze (Hersteller: Fa. H. Kaiblinger, München) durch einen Stanzvorgang 40 Startlöcher und 20 Antiserumkanäle ausgestanzt. Die Grundplatte der Stanze dient gleichzeitig als nivellierbare Unterlage beim Gießen des Agarsols und als Stanzentisch. Die Anordnung der Startlöcher zum Antiserumkanal ist bei einer bestimmten Mindestlaufzeit auf den diagnostischen Bereich $\operatorname{der} \alpha_{1}-, \alpha_{2}$ - und zum Teil der $\beta_{1}$-Globulinfraktionen abgestimmt. Dadurch wird eine antiserumeinsparende Verkürzung der Kanäle auf $30 \mathrm{~mm}$ ermöglicht (Abb. 1). $\mathrm{Da}$ - entsprechend den Richtlinien des Bundesgesundheits- amtes - immer 2 Platten gleichzeitig unter Verwendung zweier verschiedener Immunseren elektrophoretisch anfgetrennt werden, lassen sich in einem Untersuchungsgang maximal 80 Einzelbestimmungen vornehmen.

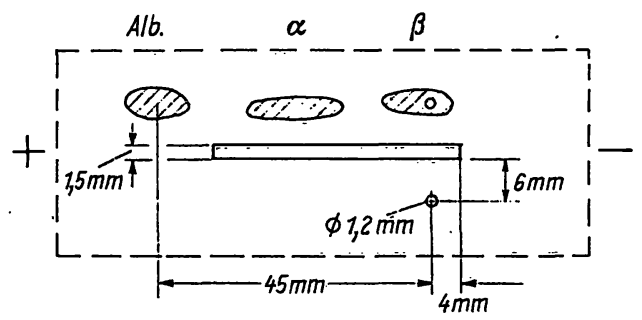

Abb. 1

Schematische Darstellung der Maße eines Stanzmusters und der geforderten Laufstrecke des Albumins. Der Antiserumkanal ist $30 \mathrm{~mm}$ lang

\section{Elektrophorese}

Obwohl der Handel eine Fülle von Trennkammern anbietet, bedienen wir uns nach wie vor des von Schlesrnger u. a. (15) angegebenen improvisierten Verfahrens über Glasschalen als Puffergefäße. Nach Absaugen des Agars aus den vorgestanzten Startlöchern mit einer an eine Wasserstrahlpumpe angeschlossenen Saugnadel (abgefeilte Injektionskanüle) werden jeweils 2 Glasplatten parallel unter fortlaufender Numerierung der Probandenseren beimpft. Sobald das Serum etwas in das Gel diffundiert ist, wird ein Mikrotropfen einer gesättigten Bromphenolblaulösung in mindestens 2 der jeweils 8 in einer Reihe liegenden Startlöcher gegeben. Bromphenolblau wandert bei der elektrophoretischen Auftrennung mit dem Albumin; es dient als Indikator für die Laufstrecke.

Die Platten werden sodann, mit den Startlöchern zur Kathode hinzeigend, parallel über 2 etwa $2 \mathrm{~cm}$ hoch mit Elektrodenpuffer gefüllte Instrumentenschalen $(28 \times 12 \mathrm{~cm})$ gelegt und durch besonders dicke und saugfähige, zugleich gut biegsame Filterkartonstreifen (Schleicher \& Schüll, Nr. 2668), die etwa $1 \mathrm{~cm}$ breit der Gelschicht aufliegen, mit dem Puffer verbunden. Als Elektroden dienen Platindrähte, die zur Gewährleistung einer gleichmäßigen Feldstärke das ganze Puffergefäß durchlaufen. Bei dieser Versuchsanordnung wird eine optimale Auftrennung erreicht, wenn die Laufstrecke $z$ wischen dem Startloch und dem ,markierten"Albumin etwa $45 \mathrm{~mm}$ beträgt (Abb. 1). Sobald nach Beginn der Elektrophorese das zu untersuchende Serum vollständig in das Gel hineindiffundiert ist, werden die Geloberflächen und das Überleitungspapier bis dicht an die Pufferoberfläche mit einer transparenten Plastikfolie bedeckt (Abb. 2). Die Trennung dauert bei einem Spannungsgradienten von 7 Volt $/ \mathrm{cm}$ und einem Stromdurchgang von etwa $20 \mathrm{~mA}$ je Platte 2 bis $21 / 4$ Stdn. Eine Kühlung während der Elektrophorese ist nicht erforderlich, da nur eine geringe $\mathrm{Er}_{\mathrm{r}}$ wärmung des Gels eintritt.

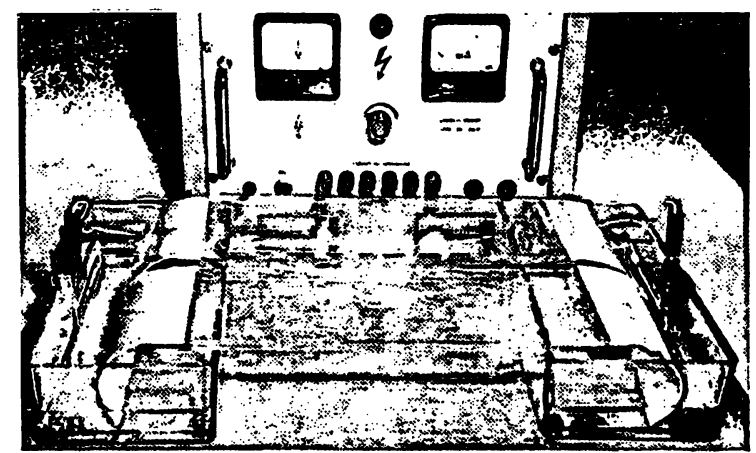

Abb. 2

Eine einfache, aber zweckmäßige Elektrophoreseapparatur. Gel und Filterkarton sind mit einer durchsichtigen Plastikfolie bedeckt 


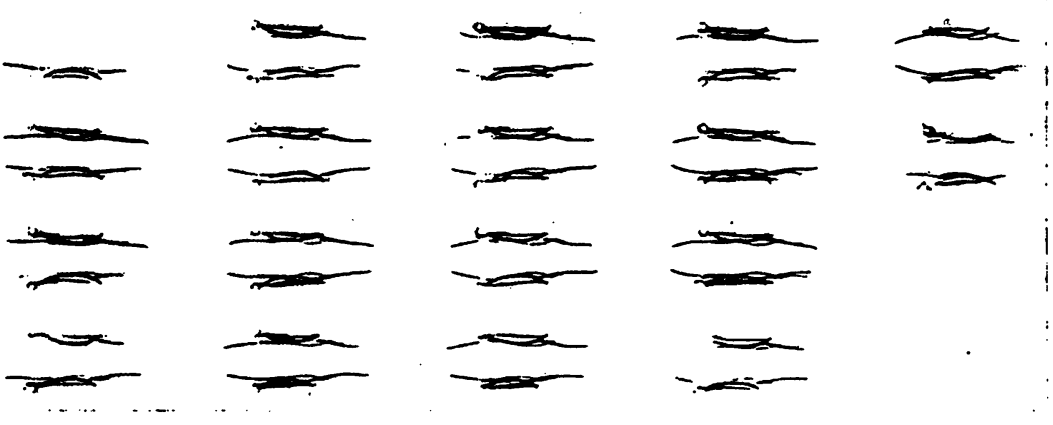

Die weiteren Arbeitsgänge entsprechen der bei der Immunelektrophorese im Agargel üblichen Technik: Ausheben der vorgestanzten Antiserumkanäle; "Eingeben der Antiseren; Präzipitation in feuchter Kammer für etwa 24 Stdn.; Auswaschen der überschüssigen, nichtpräzipitierten Serumreste in 0,9 proz. Kochsalzlösung; Bedecken des Gels mit feuchtem Filterpapier; Trocknen bei Zimmertemperatur oder unter einem Ventilator; Anfärben der Präzipitate mit Azocarmin oder Amidoschwarz; Auswertung der gefärbten Präzipitatmuster auf einem Lichtkasten.

\section{Diskussion}

Die Vorteile dieser Variante der Mikromethode bei der an sich schon umständlichen und zeitraubenden GcDiagnostik sind nicht zu übersehen. Sie erleichtert das Ablesen der jeweils in 8 Reihen untereinander angeordneten Muster und auf einen Blick den Vergleich mit den Kontrollseren. Sie erlaubt außerdem eine übersichtliche photographische Registrierung (Abb. 3). Da es ausreicht, auf jeder Glasplatte 3 Standardseren mitzuführen, ergibt sich eine zusätzliche Einsparung von Antiserum. Ein Nachteil des Verfahrens liegt darin, daß bei geringer Serumprobenzahil ein gewisser Agarverlust in Kauf genommen werden muß.

Antihumanseren, die besonders im $\alpha_{2}$-Globulinbereich zahlreiche Präzipitatlinien hervorrufen und durch Überlagerung der Gc-Linien ohnehin die Ablesbarkeit erschweren, sind für diese Mikromethode nicht geeignet; sie können gelegentlich zu Fehlbestimmungen führen. Das gilt auch für die monospezifischen Anti-Gc-Seren. Nach Cteve (3) sollte das ideale Antiserum Antikörper gegen mindestens 4 verschiedene Plasmaproteine enthalten, und zwar neben einem Gc-Antikörper auch Antikörper gegen Albumin (oder $\alpha_{1}$-Glykoprotein), $\alpha_{2}$ Makroglobulin und Transferrin, gegen die Proteine also, die auch als sog. Leitpräzipitate oder Bezugsbögen gelten. Mittlerweile sind mehrere käufliche Seren verfügbar, die zum Teil diese Forderung erfüllen (Behringwerke Marburg, Serpasteur-Paris, Biotest-Serum-Institut Frankifurt, Molter-Heidelberg, Dade-Bern).

Eindeutige Ergebnisse setzen eine optimale Trennung des $\alpha_{1}$ - und $\alpha_{2}$-Globulinbereiches bei ausreichend langer Laufzeit voraus. Es hat sich eingebürgert, bei der Darstellung der Haptoglobine die Stromstärke, bei Auftrennung der gruppenspezifischen Komponente den Spannungsabfall als Richtgröße zu empfehlen. Die in der Literatur angegebenen Auftrennungszeiten schwanken zwischen $45 \mathrm{Min}$, u. 41/2 Stdn. Da diese unterschiedlichen Angaben auf die Variation der Versuchsanordnungen zurückzuführen sind (Spannungsabfall, Puffersystem,
Elektrolytkonzentration der Puffer, Agarkonzentration, Schichtdicke und Flächenausdehnung des Agargels), müssen sich zwangsläufig unterschiedliche Wanderungsstrecken der Proteine und daher auch Verschiebungen der Gc-Linien in ihrer Lage zu den Bezugsbögen ergeben. $\mathrm{Da}$ ferner selbst bei scheinbar gleichen Versuchsbedingungen die Auftrennungszeiten durch Erwärmung und Wasserverlust des Gels variieren können, wäre es sinnvoller, eine bestimmte Laufstrecke als konstante Richtgröße festzulegen. Dies geschieht am besten dadurch, daß man das Albumin, wie bereits erwähnt, mit Bromphenolblau „markiert" und die optimale Auftrennung empirisch ermittelt. Das Abdecken der Agargelschicht und der Filterkartonstreifen mit einer transparenten Plastikfolie hat sich dem geschlossenen System in einer Elektrophoresekammer als überlegen erwiesen. Konstante Spannungs- und Stromverhältnisse während der Auftrennungszeit zeigen an, daß kein nennenswerter Wasserverlust (und auch keine wesentliche Erwärmung) auftritt. ReInskou (14) hat dagegen bei einer Auftrennungszeit von $120 \mathrm{Min}$. und einem Spannungsgradienten von $8 \mathrm{Volt} / \mathrm{cm}$ in der Elektrophoresekammer einen Wasserverlust des Gels von 35\% als unterste Grenze beobachtet.

Unbrauchbare Resultate können auf technische, leicht zu behebende Fehlerquellen zurückzuführen sein, die bei Verwendung einer geschlossenen, mit Sicherheitsschalter versehenen Elektrophoreseapparatur nicht erkannt werden, zumal wenn das Abdeckglas beschlägt. Es kommt nämlich gelegentlich in den ersten Minuten der Elektrophorese infolge einer Durchmischung des Probandenserums mit: Puffer zu einer überschießenden Anfüllung der Startlöcher. Das auf diese Weise verdünnte Serum kann sich auf der Geloberfläche zum Antiserumkanal hin ausbreiten, diffundiert nach einiger Zeit wieder in das Gel und wird nun in wesentlich kürzerem Abstand zum Kanal elektrophoretisch aufgetrennt. Nach Diffusion des Antiserums sieht man dann der Kanalwand dicht anliegende, kaum differenzierbare Präzipitate. Durch kurzes Abtupfen des überschüssigen Serums läßt sich dieser Fehler vermeiden.

Es ist bekannt, daß im elektrischen Feld die Wanderungsgeschwindigkeit der Proteine der anodenwärts aufgetragenen Serumproben im Gegensatz zu den kathodennahe eingebrachten Seren etwas geringer ist. Auch hier kann man durch die „Markierung“ des Albumins ein wenig „interpolieren“. Der Unterschied ist jedenfalls niemals so groß, daß er sich erschwerend auf die Diagnostik aus- 
wirken könnte. Obwohl man annehmen sollte, daß bei dieser immunologischen Reaktion das Präzipitationsoptimum bei etwa $37^{\circ}$ liegt, zeigen offenbar die Reaktionsansätze im Kühlschrank und bei Zimmertemperatur gleichbleibend gute Ergebnisse.

Vergleichende eigene Untersuchungen haben die Beobachtung Cleves (3) bestätigt, daß der von HirschFELD $(8,9)$ modifizierte Barbital-Calciumlactatpuffer nach LAURELL (10) die $\alpha_{2}$-Globulinfraktionen gegenüber dem Michaelis-Puffer eindeutig besser auftrennt. $\mathrm{Da}$ bei gleichbleibendem Spannungsgradienten von etwa 7 Volt/ $\mathrm{cm}$ bei diesen beiden Puffersystemen mit unterschiedlicher Elektrolytkonzentration erhebliche Veränderungen der elektrischen Widerstände auftreten, differieren bei konstanter Laufstrecke die Laufzeiten um etwa eine halbe Stunde (Michaelis 110 Min., LaUReLr 140 Min.). Zunächst fällt auf, daß offenbar alle $3 \mathrm{Gc}$-Typen links schneller anodenwärts gewandert sind, als rechts (Abb. 4).

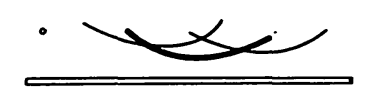

GC 1-1
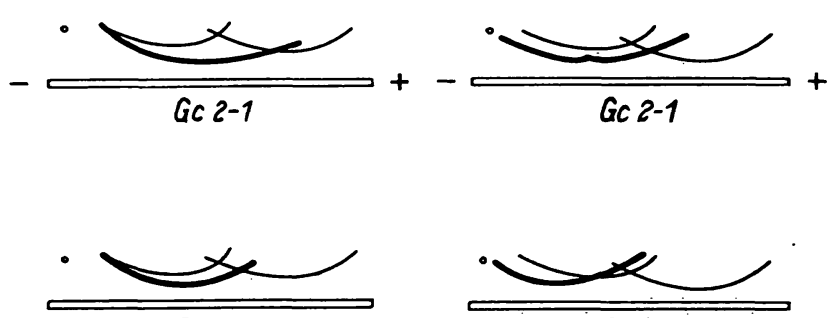

Gc 2-2

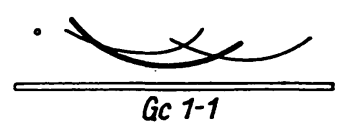

Gc 1-1

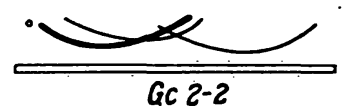

Abb. 4

Schema der Lage der Präzipitationsbögen zueinander bei MichaelisPuffer (links) und Laurell-Puffer (rechts) - (hier als sog. Bezugsbögen nur das $\alpha_{2}$-Makroglobulin und das $\alpha_{1}$-Glykoprotein eingezeichnet)

Während sich die 1-1-Typen weniger unterscheiden, zeigt der Gc-Typ 2-2 rechts gegenüber dem linken Typ bei wesentlich langsamerer Wanderungsgeschwindigkeit die größte Gegensätzlichkeit. Der intermediäre Typ 2-1 hat rechts ein charakteristisches, zweigipfeliges Präzipitat, das sich über den ganzen Bereich des $\alpha_{2}-$ Makroglobulins erstreckt, während der linke Gc-Typ 2-1 ein flaches, langgestrecktes und mehr anodenwärts liegendes Präzipitat aufweist. Jedoch ist dieses Phänomen offensichtlich nicht vom Puffersystem abhängig; denn nach optimaler Auftrennung kann auch bei Anwendung des Michaelis-Puffers eine doppeltgekrümmte Präzipitatlinie für den Typ 2-1 entstehen. Bundschur und Mitarbeiter (2) haben schon darauf hingewiesen, daß die Frage, warum in einem Fall eine langgestreckte und im anderen Fall eine doppeltgekrümmte Linie für den GcTyp 2-1 entsteht, noch ungeklärt ist. In jedem Falle bietet die Anwendung des Barbital-Calciumlactatpuffers eine wesentlich bessere Typendifferenzierung und damit eine erhöhte Sicherheit in der Diagnostik (Abb. 5). Selbst nach unzureichender. Auftrennungszeit, aber wiederum konstanter Laufstrecke des Albumins bei

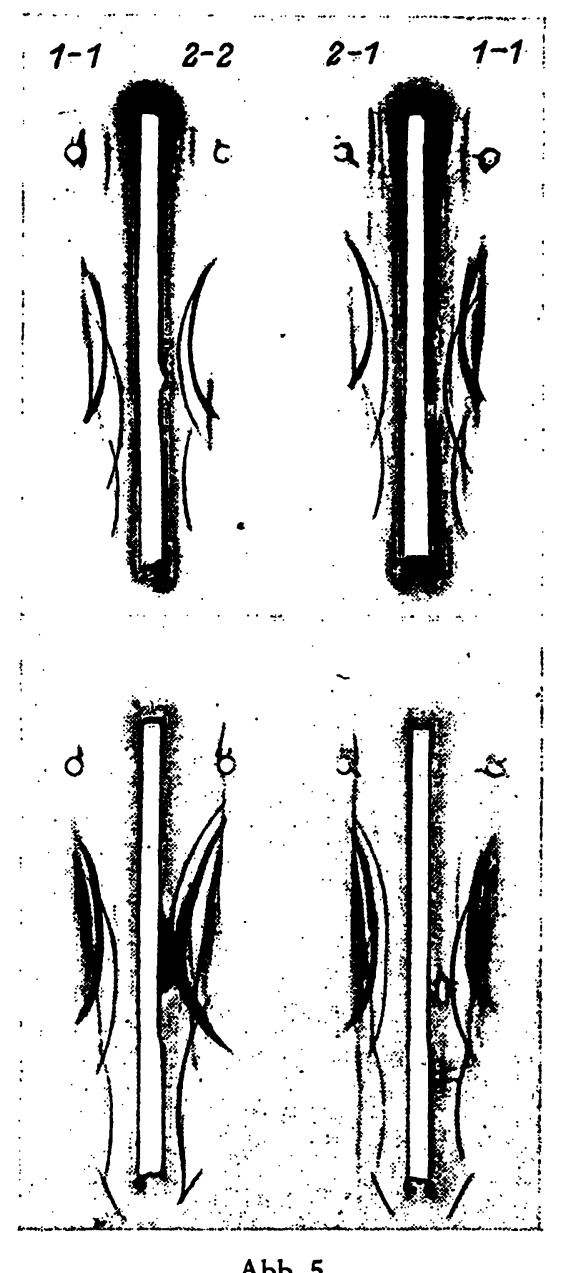

Abb. 5

Darstellung der Gc-Typen mit Michaelis-Puffer (links) und LaurellPuffer (rechts) nach gleich weiter Auftrennung

beiden Puffersystemen, gewährleistet der LaurellPuffer noch eine eindeutige Differenzierung, während bei Anwendung des Michaelis-Puffers sogar die Erkennung des 2-2-Typs gelegentlich erschwert sein kann (Abb. 6). Eine Gegenüberstellung der Muster zeig+ jedenfalls deutlich, daß nach Verlängerung der Laufzeiten die Verschiebung der Gc-Linie der 3 Typen insgesamt zur Anode hin bei Michaelis-Puffer größer, und damit ihre Lage zu der Hauptleitlinie, dem $\alpha_{2}$-Makroglobulin, undifferenzierter ist als beim Laurell-Puffer (vgl. Abb. 5 und 6).

HeIfer (6) hat hervorgehoben, daß unter gleichen Versuchsbedingungen das Gc 2-1-Präzipitat gewisse, technisch bedingte Formänderungen aufweisen kann, so daß eine Abgrenzung eines $\mathrm{Gc} 1-1$-Typs von einem Gc 2-1 manchmal schwierig ist. Offenbar bestehen aber auch vom Antiserum abhängige Formvariationen. Meistens gelingt nämlich die Differenzierung eines strittigen Gc-Musters durch eine Zweitbestimmung mit einem anderen Antiserum, so da $\beta$ ein Verifikationstest überflüssig wird (Abb. 7). Sogar die Paralleluntersuchung eines Serums vom Typ 1-1 mit 2 verschiedenen Antiseren zèigte ein unterschiedliches Verhalten der GcLinien (Abb. 8). Die Wanderungsgeschwindigkeit der Fraktionen war, wie zu erwarten, gleich, jedoch beginnen die obengelegenen 1-1-Typen mit einem Überschneiden 

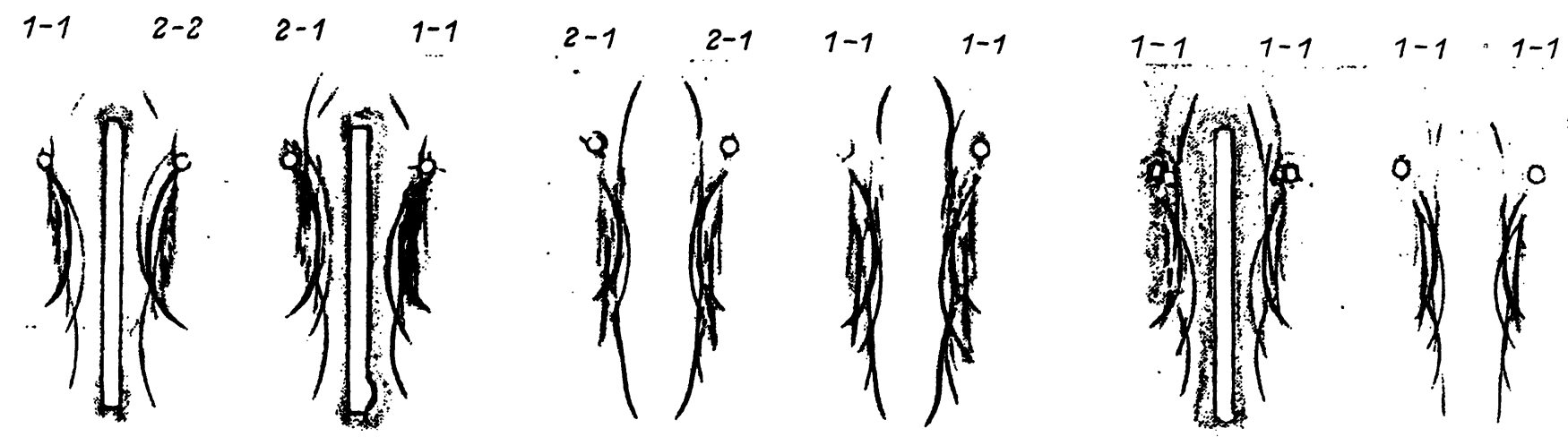

Abb. 8

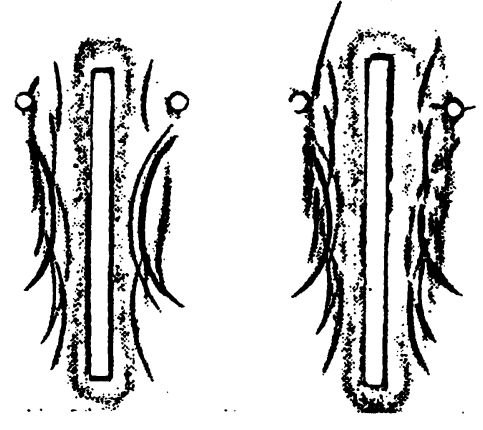

Abb. 6

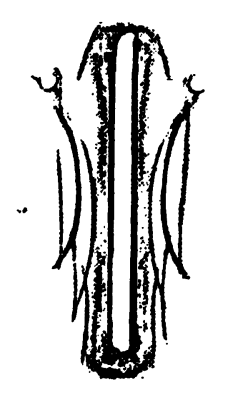

Abb. 6

Darstellung der Gc-Typen mit Michaelis-Puffer (links) und Laurell-Puffer (rechts) nach zu kurzer Auftrennung

Abb. 7

Doppeluntersuchung zweier Seren vom Typ 1-1 und 2-1 mit zwei verschiedenen Antiseren. Die beiden 2-1-Muster (links unten) lassen ohne Kontrolle des Befundes mit einem zweiten unten)

Abb. 8

Formänderungen desselben Probandenserums vom Typ 1-1 bei zwei verschiedenen Antiseren des $\alpha_{2}$-Makroglobulins, während die untengelegenen 1--1-Typen das $\alpha_{2}$-Makroglobulin kathodenwärts nur berühren.

Transformationen der Gc-Präzipitate durch Temperatureinflüsse und durch freigesetzte, proteolytische Enzyme aus Leukocyten, Thrombocyten und einigen Bakterien sind bekannt [Nerström, LeIthoff $(11,12)$ sowie Heifer u. Bolkenius (7)]. Die Untersuchungen beziehen sich jedoch hauptsächlich auf Blutspuren, Leichenblut und lange gelagerte Blutspuren. Neuerdings haben Forster und JoAchim (5) alternde Serum- und Vollblutproben systematisch untersucht: bereits nach wenigen Tagen Lagerung bei Zimmertemperatur traten proteolytische Veränderungen der Gc-Präzipitate und des $\alpha_{2}$-Makroglobulins auf, so daß durch „Umwandlung“ der Proteine mit unterschiedlicher Wanderungsge- schwindigkeit Fehldiagnosen drohen. Derartige Veränderungen haben auch wir öfters an älteren Seren beobachtet. Ein hämolytisches Blut kann durchaus noch brauchbare Ergebnisse liefern, aber die Hämolyse kann ein Hinweis für eine bereits vorhandene oder bevorstehende Desintegration der Leukocyten und Thrombocyten sein. Es ist daher eine gewisse Vorsicht bei der Gc-Klassifizierung hämolytischer und solcher Seren geboten, die durch Postversand mehrere Tage lang sommerlichen Temperaturen ausgesetzt waren, da bei diesen gelegentlich eine Serumproteolyse zu erwarten ist. Seren frisch entnommener Blutproben sind in eingefrorenem Zustand bei Temperaturen unter $-15^{\circ}$ jahrelang haltbar und liefern auch nach wiederholtem Auftauen stets reproduzierbare Ergebnisse.

\section{Literatur}

1. Bartsch, H., J. Klose, K: Omoto und H. Ritrer, Ärztl. Laborat. 10, 42 (1964). - 2. BundSCHUH, G., Z. M.AREK und G. GESERICK, Ärztl. Laborat. 9, 181 (1963). - 3. CleVE, H., Die gruppenspezifischen Komponenten des menschlichen Serums. HüthigVerlag Heidelberg (1965). - CLEVE; H., Die Klassifizierung der gruppenspezifischen Komponenten. Vortr. 4. Tagg. Arb.gemeinsch. gerichtl. Blutgruppensachverständiger, Bad Homburg 1966 Kongreßbericht. - 4. Enged, R., Dtsch. med. Wschr. 91, 2125 (1966). - 5. Forster, B. und H. JOACHIM, Immunoelektrophoretische Veränderungen lagernder Serumproben und ihre Bedeutung für die Diagnostik der Gc-Eigenschaften. Vortr. 45. Kongr. Ges. gerichtl. Med., Freiburg 1966, Zschr. gerichtl. Med., Wien Kongreßband, im Druck. - 6. HeIfer, U., Zschr. gerichtl. Med., Wien 57, 214 (1966). - 7. HeIFer, U. und M. BolkenIUs,
Zschr. gerichtl. Med., Wien 58, 76 (1966). - 8. HirsChFELD, J., Acta pathol. microbiol. scand. 47, 160 (1959). - 9. Hirschfeld, J., Science Tools 7, 18 (1960). - 10. Laurell, C. B., S. Laurell und N. Skoog, Clin. Chem. (New York) 2, 99 (1956). - 11. LerTHOFF, H. und J. LerthofF, Zschr. gerichtl. Med., Wien 54, 286 (1963): - 12. Nerström, B., Acta pathol. microbiol. scand. 57, 495 (1963). - 13. NerSTröM, B., Acta path. microbiol. scand. 60, 540 (1964). - 14. Reinskou, T., Vox Sang. 11, 70 (1966). Richtlinien für die Erstattung von Blutgruppengutachten. Bundesgesundheitsblatt 7, 215 (1964). - 15. S.CHLESINGER, D., A. VoGT und O. Prokop, Dtsch. Gsd.wes. 18, 332 (1963). - 16. Stöss, B., H. J. Pettenkofer und H. Piche, Zbl. Bakt. Abt. I Orig. 197, 411 (1965).

Dr. R. Hilgermann 355 Marburg, Mannkopffstr. 2 